\title{
Treatment of proximal femoral fractures in children delbet type ii by ilizarov technique
}

\begin{abstract}
Hip fractures rarely occur in children but when it occurs it is potentially very serious. Fracture in children is due to high velocity trauma, for example falling from a height or a car accident. Among the high risk complications we can get avascular necrosis, premature physeal closure and coxa vara when we use screws. Between the age of 4 and 9 the ligamentous teres contributes very little to the blood supply of the epiphysis, hence it is prone to post traumatic ischaemia. We treated a 10 years old boy who fell from height and admitted in Bari-Ilizarov Orthopaedic Centre on 02.06.2017, 3 months back. We treated the boy within 18 hours as urgency by Ilizarov technique under image intensifier by closed reduction and fixation with $1.5 \mathrm{~mm} 6$ multiple Ilizarov wires. These Ilizarov wires were fixed with 6 hole plates which was fixed with two full rings, placed in the lower region of femur.
\end{abstract}

Volume 9 Issue I - 2017

Bari MM, ${ }^{1,2}$ Islam Shahidul, ${ }^{2}$ Shetu $\mathrm{NH}^{2}{ }^{2}$ Mahfuzer RM ${ }^{2}$

'Consultant, Bari-Ilizarov Orthopaedic Centre, Bangladesh ${ }^{2}$ Prof. Ph.D, Chief Consultant, Bari-llizarov Orthopaedic Centre, Visiting and Honored Prof., Russian Ilizarov Scientific Centre, Russia

Correspondence: Bari MM, Chief Consultant, Bari-llizarov Orthopaedic Centre,Visiting and Honored Professor Russian Ilizarov Scientific Centre, Kurgan, Russia, Tel 8800000000000 Email bariilizavro3।@gmail.com

Received: September II, 2017 | Published: September 19, 2017

\section{Classification}

Delbet's classification is most useful which is based on the level of the fracture. ${ }^{1}$ Ingram and Bachynski in 1975 used same classification and this was popularized by Colonna. ${ }^{2}$

A. Type-I: Separation of the epiphysis; sometimes the epiphyseal fragment is dislocated from the acetabulum.

B. Type-II: Trans cervical fracture of the femoral neck; this is the commonest variety. Osteonecrosis development is very common in this type and it is $52 \%{ }^{3}$

C. Type-III: Basal (cervico -trochanteric) fracture, the second most common injury (Figure 1).

D. Type-IV: Intertrochanteric fracture.

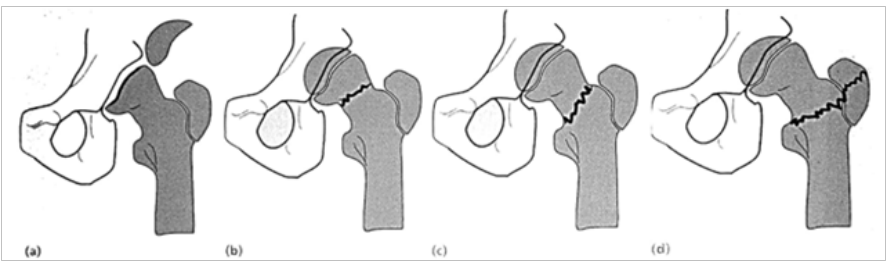

Figure I Proximal femoral fractures in children. These are the result of strong forces or weak bone, e.g. through cysts. There are 4 types (the Delbet classification), depending on the level of the fracture: (a) type-I at the physeal level; (b) type-II through the middle of the neck; (c) type-III at the base of the neck and (d) type-IV at the intertrochanteric level.

\section{Clinical features}

In infants diagnosis can be difficult were the epiphysis is not easily defined on x-ray. Type-I fractures are easily mistaken for hip dislocation, USG, MRI and arthrography may help. In older children the diagnosis is usually obvious on plain x-ray. Type-IV fractures are the least likely to give rise to complications.

\section{Treatment}

These fractures must be treated as urgency. Definitely within 24 hours of injury. Displaced type-IV can also be treated non-operatively, closed reduction, traction and spica immobilization. But Type-I, II and II fractures are treated by closed reduction and then internal fixation with smooth pins or cannulated screws, closed reduction means one gentle manipulation, if this fails, open reduction is performed. In small children, operative fixation is supplemented by a spica cast for 6-12 weeks.

\section{Our technique of ilizarov fixation}

Under fluoroscopic control we reduced the fracture fragment by gentle manipulation and multiple $1.5 \mathrm{~mm} 6$ Ilizarov wires inserted below the greater trochanter upto physis to fix the fragments. 6 Ilizarov wires were inserted. 2 Ilizarov rings were fixed in the lower femur with 2 counter opposed $1.8 \mathrm{~mm}$ olive wires in each ring. After that all the Ilizarov wires through the neck was fixed with 6 hole plates and the plate was attached with the ring and it was kept for $2 \frac{1}{2}$ months. Patient could move with Ilizarov frame easily. Ilizarov frame was dismounted after $2 \frac{1}{2}$ months and a temporary hip spica was applied for 2 weeks. ${ }^{4,5}$

\section{Results}

Excellent union was achieved within 3 months (Figure 2-5).

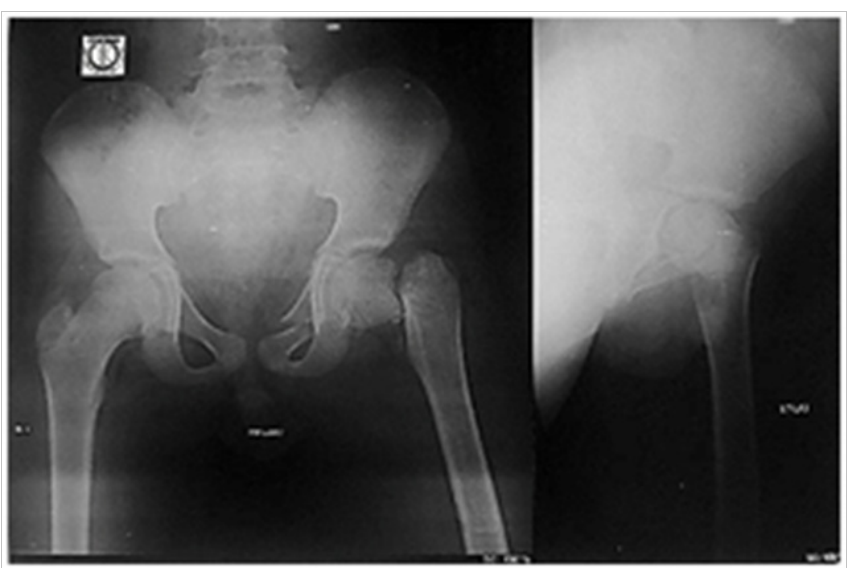

Figure 2 Delbet type-II. 


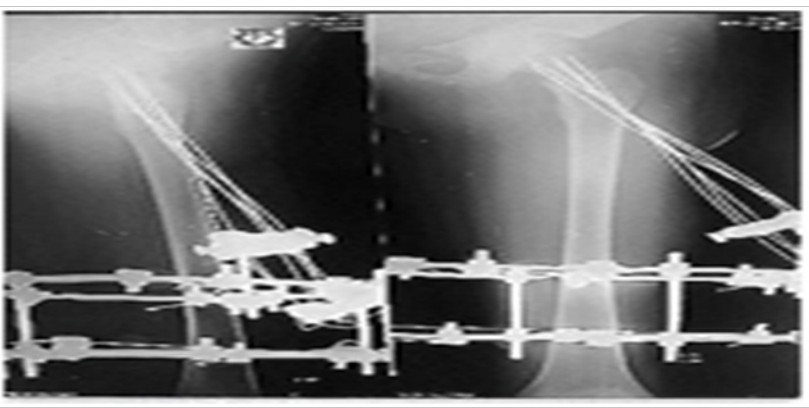

Figure 3 During treatment with llizarov frame.

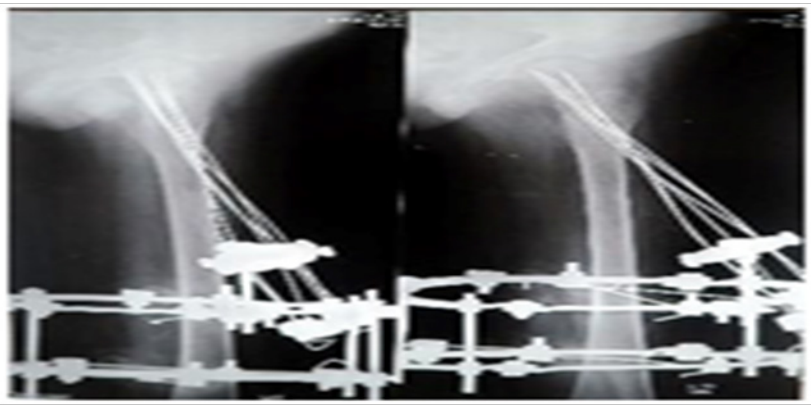

Figure 4 After $2 \frac{1}{2}$ months union achieved.

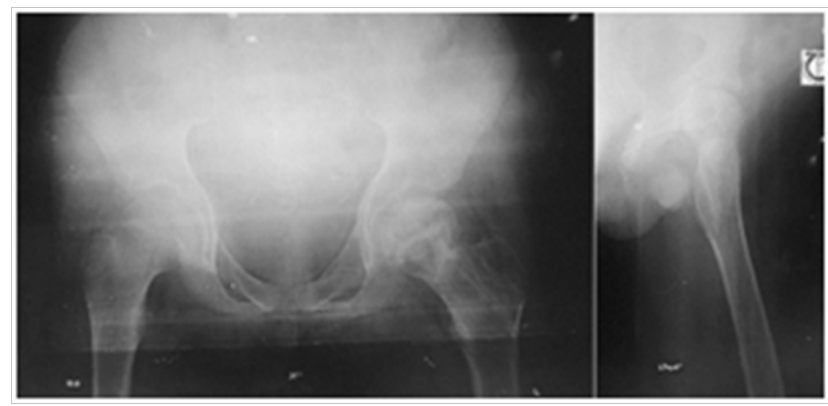

Figure 5 After removal of Ilizarov fixation, good union is achieved.

\section{Complications}

Avascular necrosis is the most common and must feared complication it occur in $30 \%$ of all cases with cannulated screw fixation.

\section{Risk factors}
A. An age of more than 10 years.
B. A high velocity injury
C. A type I or II fracture
D. Gross displacement

The child complains of pain and loss of movement. Radiographic changes appear within 3 months of injury. Coxa vara may develop; if deformity is mild remodeling may happen. If the NSA (Neck shaft angle) is less then $110^{\circ}$ subtrochanteric valgus osteotomy may be needed.

\section{Diminished growth}

Physeal damage may lead to limb length discrepancy that may be needed for equalization.

\section{Discussion}

The blood vessels to the femoral head are easily damaged and a high incidence of osteonecrosis occurs in cervical and transepiphyseal fractures in children, even higher than in adults. ${ }^{6}$ Growth arrest in the physis can cause shortening of $15 \%$ of the total extremity. Varus or valgus angulation of the femoral neck also can occur from arrest of only one side of the physis. Hip fractures in children also differ from fractures in adults because a child can tolerate immobilization much more than an adult. Internal fixation with threaded pins in a child can be used to secure firm fixation of the femoral neck. In a child this can cause premature physeal closure and significant leg length in equality. According to Boitzy capsular distention and subsequent tamponade of the vessels may increase the incidence of osteonecrosis. ${ }^{4}$ TypeII transcervical fractures were at greater risk (50\%) than type- III fracture. Gerber et al. ${ }^{5}$ concluded that immediate open reduction and internal fixation did not prevent osteonecrosis after displaced typeII and III fractures. ${ }^{5}$ Internal fixation is recommended for all type II fractures because most are unstable. Non-union also can occur if internal fixation is not used. A gentle closed reduction should be done with longitudinal traction, abduction and internal rotation followed by fixation with $1.5 \mathrm{~mm}$ multiple Ilizarov wires. We have done all these with the use of an image intensifier. The head and neck of a child's femur are extremely hard and that's why we avoided other devices for fear of distraction of the fracture and possible separation of the capital femoral epiphysis. Ilizarov's wire holds the fragments nicely and because of numerous problems with noncompliance, a hip spica cast is used for 6-8 weeks, but in Ilizarov fixation it is not needed.

\section{Conclusion}

Thin biocompatible 1.5 Ilizarov wires give excellent result with less complication.

\section{Acknowledgments}

None.

\section{Conflicts of interest}

None.

\section{References}

1. Hughes LO, Beaty JH Fractures of the head and neck of the femur in children. J Bone Joint Surgery Am. 1994;76(2):283-292.

2. Colonna Pc Fractures of the neck of the femur in children. Am J Surg. 1929;6:793.

3. Morrissy $\mathrm{R}$ Hip fractures in children. Clin Orthop Relat Res. 1980;202-210.

4. Boitzy A Fractures of the proximal femur. In: Weber BG, et al. (Eds.), Treatment of fractures in children and adolescents, Springer Verlog, New York, USA. 1980

5. Gerber C, Lehmann A, Ganz R Femoral neck fractures in children: experience in 7 Swiss AO hospitals. Orthop Trans. 1985;9:474.

6. Chunk SMK The arterial supply of the developing proximal end of the human femur. J Bone Joint Surg. 1976;58(7):961-970. 